\title{
CDCA3 mediates p21-dependent proliferation by regulating E2F1 expression in colorectal cancer
}

\author{
WENWEI QIAN ${ }^{1,2^{*}}$, ZHIYUAN ZHANG ${ }^{1,2^{*}}$, WEN PENG $^{1,2^{*}}$, JE LI ${ }^{1,2}$, QIOU GU ${ }^{1,2}$, DONGJAN JI ${ }^{1,2}$, \\ QINGYUAN WANG ${ }^{1,2}$, YUE ZHANG ${ }^{1,2}$, BING JI $^{1,2}$, SEN WANG $^{1,2}$, \\ DONGSHENG ZHANG ${ }^{2}$ and YUEMING SUN ${ }^{2}$ \\ ${ }^{1}$ The First School of Clinical Medicine, Nanjing Medical University; ${ }^{2}$ Department of General Surgery, \\ The First Affiliated Hospital of Nanjing Medical University, Nanjing, Jiangsu 210029, P.R. China
}

Received March 28, 2018; Accepted July 23, 2018

DOI: $10.3892 /$ ijo.2018.4538

\begin{abstract}
Dysregulated cell cycle progression serves a crucial role in tumor development. Cell division cycleassociated 3 (CDCA3) is considered a trigger of mitotic entry; it is an important part of the $\mathrm{S}$ phase kinase-associated protein 1/Cullin/F-box ubiquitin ligase complex and mediates the destruction of mitosis-inhibitory kinase weel. However, little is known about the role of CDCA3 in cancer, particularly colorectal cancer (CRC). The present study aimed to explore the biological and clinical significance of CDCA3 in $\mathrm{CRC}$ growth and progression. CDCA3 expression was significantly associated with tumor progression and poor survival. Overexpression of CDCA3 increased proliferation in LoVo CRC cells, whereas CDCA3 knockdown in SW480 CRC cells led to decreased proliferation, in vitro and in vivo. Further mechanistic investigations demonstrated that reduced CDCA3 expression resulted in G1/S phase transition arrest, which was attributed to a significant accumulation of p21 in SW480 cells; conversely, increased CDCA3 expression promoted G1/S phase transition through decreased p21 accumulation in LoVo cells. It was also demonstrated that CDCA3 was able to regulate the expression of transcription factor E2F1, thereby repressing p21 expression. Taken together, these results suggested that overexpression of CDCA3 may serve a crucial role in tumor malignant potential and that CDCA3 may be used as a prognostic factor and a potential therapeutic target in CRC.
\end{abstract}

\section{Introduction}

Despite the known pathogenic risks and the development of progressive therapeutic strategies, colorectal cancer (CRC)

Correspondence to: Dr Yueming Sun, Department of General Surgery, The First Affiliated Hospital of Nanjing Medical University, 300 Guangzhou Road, Nanjing, Jiangsu 210029, P.R. China

E-mail: jssym@vip.sina.com

Key words: colorectal cancer, cell division cycle-associated 3, transcription factor E2F1, p21, cell cycle, cell proliferation, oncogene has the fourth highest incidence rate among all cancers and the fifth highest incidence rate of tumor-related mortalities in China (1-3). CRC development involves a complex transformation of molecular events; increasing our understanding of the molecular mechanisms involved in tumor formation and progression will contribute to the development of novel therapeutic targets.

Aberrant cellular growth and division are common features in malignant cells, including CRC cell lines (4). Cell cycle phase progression relies on a complex network of regulatory proteins, and the relationship between tumorigenesis and these molecules has been reported in a number of previous studies $(5,6)$. A previous attempted to target the cell cycle to suppress the prominent proliferative capacity of cancer cells (4). Combination treatments, including cell cycle mediator agents, may be a potential model for improved curative effects.

Cell division cycle-associated protein 3 (CDCA3) is referred to as a 'trigger' of mitotic entry, and has been reported to mediate cell cycle progression (7). CDCA3 functions as a part of $\mathrm{S}$ phase kinase-associated protein 1/Cullin 1/F-box (SCF) E3 ubiquitin ligase complex to mediate destruction of the mitosisinhibitory kinase wee1, thus imparting an important effect on the cell cycle (7-11). SCF E3 ligases regulate numerous shortacting proteins, such as cell cycle regulators, and mediate several biological processes, including cancer cellular activities (12). An increasing number of reports have demonstrated that CDCA3 expression is increased in liver cancer (13), oral squamous cell carcinoma tissue (14), non-small cell lung cancer (15) and prostate cancer cells (16), and may be associated to malignant diseases. However, the role of CDCA3 in $\mathrm{CRC}$ remains unclear. In the present study, the role of CDCA3 in $\mathrm{CRC}$ was examined, and the data provide evidence that irregular CDCA3 expression may be common in CRCs. In addition, it was demonstrated that interfering with CDCA3 expression results in alterations in cell proliferation, which suggested that CDCA3 may be a promising target for treating CRC.

\section{Materials and methods}

Tissue collection. A total of 124 CRC and 124 (71 male; 53 female; age, 23-88 years) adjacent non-tumor colorectal 
tissue samples, including a total of 84 patients that were detected in Table I, were surgically obtained between June 2009 and June 2011 at the First Affiliated Hospital of Nanjing Medical University (NJMU; Jiangsu, China). The exclusion criteria were as follows: i) histological diagnosis revealed that the tissue was not CRC; ii) patients suffered malignancies other than $\mathrm{CRC}$; iii) patients that have received preoperative radiotherapy and chemotherapy. The present study was approved by the Research Ethics Committee of NJMU and written informed consent was obtained from all patients prior to enrolment in the study. All collected tissues were frozen in liquid nitrogen immediately following surgical excision and stored at $-80^{\circ} \mathrm{C}$. Tumor, node and metastasis (TNM) stage was classified on the basis of The National Comprehensive Cancer Network guidelines (17). Patients who received any preoperative treatments were excluded from the study.

Immunohistochemistry (IHC) analysis. CDCA3 expression in $40 \mathrm{CRC}$ tissues and 40 adjacent normal specimens were detected by IHC. Immunohistochemical staining was performed using a standard immunoperoxidase staining procedure. The tissues were fixed in $10 \%$ formalin for $48 \mathrm{~h}$ at room temperature. The paraffin-embedded tumor tissue sections $(4 \mu \mathrm{m})$ were deparaffinized in xylene at $60^{\circ} \mathrm{C}$ for $3-4 \mathrm{~h}$ and rehydrated in a graded ethanol series, followed by $15 \mathrm{~min}$ of microwave antigen retrieval in a retrieval buffer $[1,000 \mathrm{ml}$ buffer comprises $2.94 \mathrm{~g}$ Tri-sodium citrate, $22.0 \mathrm{ml} 0.2 \mathrm{M}$ hydrochloric acid solution and $978 \mathrm{ml}$ UltraPure Sterile Water (Rockland Immunochemicals Inc., Limerick, Pennsylvania, USA)]. The sections were washed in phosphate-buffered saline (PBS) three times and were placed in $3 \% \mathrm{H}_{2} \mathrm{O}_{2}$ for $20 \mathrm{~min}$ in the dark, followed by three washes with PBS. The tissues were blocked in 5\% bovine serum albumin (Servicebio, Wuhan, China) for $30 \mathrm{~min}$ at room temperature. The sections were incubated with rabbit polyclonal anti-CDCA primary antibodies (1:200; cat. no. ab167037; Abcam, Cambridge, UK) overnight at $4^{\circ} \mathrm{C}$, followed by incubation with horseradish peroxidase (HRP)-conjugated polyclonal goat anti-rabbit secondary antibodies (1:1,000; cat. no. ab6721; Abcam) at room temperature for $50 \mathrm{~min}$. The sections were subsequently stained with the color agent 3,3'-diaminobenzidine and the nuclei were counterstained with hematoxylin; the sections were dehydrated using different grades of ethyl alcohol and xylene. Two experienced pathologists independently reviewed all IHC stainings under an inverted light microscope (Nikon Eclipse TI-SR; Nikon Corporation, Tokyo, Japan). The staining intensity was visually scored as follows: - (score 0$),+$ (score 1$),++$ (score 2$)$ and +++ (score 3$)$. The percentage of CDCA3-positive cells was also classified into four levels: - (0-1\%; score 0$),+(1-33 \%$; score 1$),++(34-66 \%$; score 2$)$ and $+++(67-100 \%$; score 3$)$. The final CDCA3 staining scores (Table II) were determined by the sum of the intensity and percentage scores, defined as follows: -, no expression (total score 0 ); +, weak expression (total score 1-2); ++, moderate expression (total score 3-4); and +++ , strong expression (total score 5-6).

Cell lines and cell culture. CRC cell lines SW480, LoVo, DLD-1, HCT116, Caco-2 and HT29, and the normal human colorectal epithelial cells NCM460 were maintained in our laboratory. All cell lines were cultured in Dulbecco's
Table I. Relationship between CDCA3 expression and the clinicopathological characteristics of patients with CRC.

\begin{tabular}{|c|c|c|c|c|}
\hline \multirow[b]{2}{*}{ Characteristics } & \multirow[b]{2}{*}{$\mathrm{n}$} & \multicolumn{2}{|c|}{$\begin{array}{c}\text { CDCA3 expression } \\
\text { level }\end{array}$} & \multirow[b]{2}{*}{$\begin{array}{l}\text { P-value } \\
\quad\left(\chi^{2}\right)\end{array}$} \\
\hline & & $\begin{array}{c}\text { Low } \\
(\mathrm{n}=42)\end{array}$ & $\begin{array}{l}\text { High } \\
(\mathrm{n}=42)\end{array}$ & \\
\hline \multicolumn{5}{|l|}{ Age (years) } \\
\hline$<60$ & 27 & 16 & 11 & 0.243 \\
\hline$\geq 60$ & 57 & 26 & 31 & \\
\hline \multicolumn{5}{|l|}{ Sex } \\
\hline Male & 49 & 23 & 26 & 0.507 \\
\hline Female & 35 & 19 & 16 & \\
\hline \multicolumn{5}{|c|}{ Tumor diameter $(\mathrm{cm})$} \\
\hline$<5$ & 47 & 31 & 16 & $0.001^{\mathrm{a}}$ \\
\hline$\geq 5$ & 37 & 11 & 26 & \\
\hline \multicolumn{5}{|l|}{ TNM stage } \\
\hline $\mathrm{I} / \mathrm{II}$ & 43 & 26 & 17 & $0.049^{\mathrm{b}}$ \\
\hline III/IV & 41 & 16 & 25 & \\
\hline \multicolumn{5}{|c|}{ Lymph node invasion } \\
\hline Negative & 46 & 28 & 18 & $0.028^{b}$ \\
\hline Positive & 38 & 14 & 24 & \\
\hline \multicolumn{5}{|c|}{ Depth of invasion } \\
\hline $\mathrm{T} 1+\mathrm{T} 2$ & 21 & 14 & 7 & 0.078 \\
\hline $\mathrm{T} 3+\mathrm{T} 4$ & 63 & 28 & 35 & \\
\hline \multicolumn{5}{|c|}{ Distant metastasis } \\
\hline Negative & 73 & 38 & 35 & 0.332 \\
\hline Positive & 11 & 4 & 7 & \\
\hline \multicolumn{5}{|c|}{ Primary tumor site } \\
\hline Colon & 40 & 18 & 22 & 0.382 \\
\hline Rectum & 44 & 24 & 20 & \\
\hline
\end{tabular}

${ }^{\mathrm{a}} \mathrm{P}<0.001 ;{ }^{\mathrm{b}} \mathrm{P}<0.05$. CDCA3, cell division cycle-associated protein 3 ; $\mathrm{CRC}$, colorectal cancer; TNM, tumor, necrosis and metastasis.

Table II. Statistical analysis of CDCA3 protein expression in $\mathrm{CRC}$ and adjacent normal tissues.

\begin{tabular}{lcccccc}
\hline & & \multicolumn{5}{c}{ Total score } \\
\cline { 3 - 6 } Tissue & $\mathrm{n}$ & - & + & ++ & +++ & P-value \\
\hline CRC & 40 & 8 & 10 & 19 & 3 & 0.003 \\
Adjacent normal & 40 & 16 & 16 & 7 & 1 &
\end{tabular}

tissue

CDCA3, cell division cycle-associated protein 3; CRC, colorectal cancer.

modified Eagle's medium (DMEM) supplemented with $10 \%$ fetal bovine serum (Wisent, Inc. St. Bruno, QC, Canada), $100 \mathrm{U} / \mathrm{ml}$ penicillin and $100 \mu \mathrm{g} / \mathrm{ml}$ streptomycin at $37^{\circ} \mathrm{C}$ in an atmosphere of humidified air with $5 \% \mathrm{CO}_{2}$. 
Table III. Primer sequences used for reverse transcriptionquantitative polymerase chain reaction.

Gene Sequence $\left(5^{\prime} \rightarrow 3^{\prime}\right)$

BUB1

F: AAATGACCCTCTGGATGTTTGG

R: GCATAAACGCCCTAATTTAAGCC

BUB1B

F: AAATGACCCTCTGGATGTTTGG

R: GCATAAACGCCCTAATTTAAGCC

BUB3

F: GGTTCTAACGAGTTCAAGCTGA

R: GGCACATCGTAGAGACGCAC

CCNA2

F: CGCTGGCGGTACTGAAGTC

R: GAGGAACGGTGACATGCTCAT

CCNB1

CCNB2

F: TCGCATCAAACTCTCTGGCTA

R: TGAGCGACTAAACTCACCACT

F: CCGACGGTGTCCAGTGATTT

R: TGTTGTTTTGGTGGGTTGAACT

CCNE1 F: AAGGAGCGGGACACCATGA

R: ACGGTCACGTTTGCCTTCC

CDCA3

CDC20

CDC25A

$\mathrm{CDC} 25 \mathrm{C}$

CDC45

CDC6

CDK1

CDK2

CDK4

CHEK1

CHEK2

F: TGGTATTGCACGGACACCTA

R: TGTTTCACCAGTGGGCTTG

F: GCACAGTTCGCGTTCGAGA

R: CTGGATTTGCCAGGAGTTCGG

F: GTGAAGGCGCTATTTGGCG

R: TGGTTGCTCATAATCACTGCC

F: TCTACGGAACTCTTCTCATCCAC

R: TCCAGGAGCAGGTTTAACATTTT

F: TTCGTGTCCGATTTCCGCAAA

R: TGGAACCAGCGTATATTGCAC

F: GCCGAACTAGAACAGCATCTT

R: GGGCTGGTCTAATTTTTCCTGC

F: TGGGAAGTTGGTAGCTCTGAA

R: CCAGGGTGCTTGTCCATGTA

F: TGTTTAACGACTTTGGACCGC

R: CCATCTCCTCTATGACTGACAGC

F: GGGGACCTAGAGCAACTTACT

R: CAGCGCAGTCCTTCCAAAT

F: ATATGAAGCGTGCCGTAGACT

R: TGCCTATGTCTGGCTCTATTCTG

F: TCTCGGGAGTCGGATGTTGAG

R: CCTGAGTGGACACTGTCTCTAA

E2F1 F: ACGCTATGAGACCTCACTGAA

R: TCCTGGGTCAACCCCTCAAG

E2F2

F: CGTCCCTGAGTTCCCAACC

R: GCGAAGTGTCATACCGAGTCTT

ESPL1 F: CCGCCTTGAAGGAGTTCCTG

R: GGGGTAGACACTAAGTAGCCAT

GAPDH F: GTGGACATCCGCAAAGAC

R: AAAGGGTGTAACGCAACTA

MAD2L1 F: GAGAAGTCCGAAGAAACTCACG

R: CCGAAGCGTTGAGAGGTTCC

MCM2

F: ATGGCGGAATCATCGGAATCC

R: GGTGAGGGCATCAGTACGC
Table III. Continued.

\begin{tabular}{ll}
\hline Gene & \multicolumn{1}{c}{ Sequence $\left(5^{\prime} \rightarrow 3^{\prime}\right)$} \\
\hline MCM3 & F: TCTAAGCCGCCATTTCGATTT \\
& R: AAGACGCTGGAAAGCTGGATA \\
MCM6 & F: GAGGAACTGATTCGTCCTGAGA \\
& R: CAAGGCCCGACACAGGTAAG \\
MCM7 & F: CCTACCAGCCGATCCAGTCT \\
& R: CCTCCTGAGCGGTTGGTTT \\
PKMYT1 & F: CATGGCTCCTACGGAGAGGT \\
& R: ACATGGAACGCTTACCGCAT \\
p21 & F: TGCAACTACTACAGAAACTGCTG \\
& R: CAAAGTGGTCGGTAGCCACA \\
PLK1 & F: CAGTCACTCTCCGCGACAC \\
& R: GAGTAGCCGAATTGCTGCTG \\
PTTG1 & F: ACCCGTGTGGTTGCTAAGG \\
& R: ACGTGGTGTTGAAACTTGAGAT \\
TTK & F: GTGGAGCAGTACCACTAGAAATG \\
& R: CCCAAGTGAACCGGAAAATGA \\
\hline
\end{tabular}

BUB1, BUB1 mitotic checkpoint serine/threonine kinase; BUB1B, BUB1 mitotic checkpoint serine/threonine kinase B; BUB3, BUB3 mitotic checkpoint protein; $\mathrm{CCN}$, cyclin; $\mathrm{CDC} 20$, cell division cycle; CDCA3, cell division cycle-associated protein 3; CDK, cyclin-dependent kinase; CHEK, checkpoint kinase; ESPL1, extra spindle pole bodies-like 1, separase; MAD2L1, mitotic arrest deficient 2-like 1; MCM, minichromosome maintenance complex component; PKMYT1, protein kinase, membrane-associated tyrosine/threonine 1; PLK1, polo-like kinase 1; PTTG1, pituitary tumor-transforming 1; TTK, TTK protein kinase; F, forward; R, reverse.

RNA extraction and reverse transcription-quantitative polymerase chain reaction ( $R T-q P C R)$ assays. Total RNA was extracted from $\sim 100 \mathrm{mg}$ tissues or cultured cells when they reached a density of $90 \%$ using TRIzol ${ }^{\circledR}$ Reagent (Invitrogen; Thermo Fisher Scientific, Inc., Waltham, MA, USA), according to the manufacturer's protocol. Total RNA was reverse transcribed into cDNA using the PrimeScript RT reagent kit (Takara Biotechnology Co., Ltd., Dalian, China). qPCR was performed in a $20 \mu \mathrm{l}$ volume ( $2 \mu \mathrm{l}$ cDNA; $1.2 \mu \mathrm{l}$ primers; $6.8 \mu 1 \mathrm{dH}_{2} \mathrm{O} ; 10 \mu 1$ SYBR-Green) using FastStart Universal SYBR-Green Master kit (Roche Diagnostics, Indianapolis, IN, USA) and a StepOnePlus Real-time PCR system (Applied Biosystems; Thermo Fisher Scientific, Inc.) Thermocycling conditions were as follow: Hot-start DNA polymerase activation at $95^{\circ} \mathrm{C}$ for $10 \mathrm{~min} ; 40 \mathrm{cycles}$ of $95^{\circ} \mathrm{C}$ for $15 \mathrm{sec}$ and $60^{\circ} \mathrm{C}$ for $1 \mathrm{~min}$; followed by one cycle of melt curve analysis at $95^{\circ} \mathrm{C}$ for $15 \mathrm{sec}, 60^{\circ} \mathrm{C}$ for $1 \mathrm{~min}$, and $95^{\circ} \mathrm{C}$ for $15 \mathrm{sec}$. The genespecific primer sequences are provided in Table III. The data were analyzed using the $2^{-\triangle \Delta C q}$ method (18) and the mRNA expression levels were normalized to GAPDH. All RT-qPCR reactions were performed in triplicate.

Knockdown and overexpression of CDCA3 and E2F1. Small interfering (si)RNAs against CDCA3 (siCDCA3), E2F1 (siE2F1) and negative control (siNC) were designed and synthesized by 
Shanghai GenePharma Co., Ltd. (Shanghai, China). The sequences for the CDCA3 siRNAs were as follows: SiRNA1-CDCA3, sense, 5'-GCAAUAGAUGGAAACCAA ATT-3' and antisense, 5'-UUUGGUUUCCAUCUAUUGCTT-3'; SiRNA2-CDCA3, sense, 5'-GAGUGAAGUAUUUGAAAC UTT-3', antisense, 5'-AGUUUCAAAUACUCTT-3'; siRNA3CDCA3, sense, 5'-GCUCUCCUACUCUUGGUAUTT-3', antisense, 5'-AUACCAAGAGUAGGAGAGCTT-3'; siE2F1, sense, 5'-CCUGGAAACUGACCAUCAGTT-3', antisense, 5'-CUGAUGGUCAGUUUCCAGGTT-3'; and siNC, sense, 5'-UUCUCCGAACGUGUCACGUTT-3', antisense, 5'-ACGUGACACGUUCGGAGAATT-3'. siRNAs $(5 \mu \mathrm{g} / \mathrm{ml})$ were transfected into SW480 cells using Lipofectamine ${ }^{\circledR} 3000$ (Invitrogen; Thermo Fisher Scientific, Inc.), following the manufacturer's instructions. Following incubation at $37^{\circ} \mathrm{C}$ for 2 days, assays were performed to assess the knockdown efficiency. Additionally, an inhibitor lentiviral short hairpin (sh) RNAagainstCDCA3(shCDCA3;5'-GCAATAGATGGAAACC AAA-3') synthesized by Shanghai GenePharma Co., Ltd., which was transfected into SW480 cells (shRNA-SW480) and used in in vitro and in vivo study, which was designed according to the siRNA1-CDCA3 sequence.

For the CDCA3 overexpression assays, a mammalian expression plasmid pReceiver-M02-CDCA3 (CDCA3-OE; GeneCopoeia, Inc., Rockville, MD, USA) was designed to specifically express CDCA3 and used empty vectors (pReceiver-M02-control) as the control. Plasmids $(5 \mu \mathrm{g} / \mathrm{ml})$ were transfected into LoVo cells using Lipofectamine 3000 at $37^{\circ} \mathrm{C}$ for $24 \mathrm{~h}$, according to the manufacturer's protocol. To establish cell lines that stably overexpress CDCA3 (CDCA3-SOE) or the control (control-SOE), LoVo cells that transiently transfected with pReceiver-M02-CDCA3 or pReceiver-M02-control were incubated with G418 $(400 \mu \mathrm{g} / \mathrm{ml})$ (Sigma-Aldrich; Merck KGaA, Darmstadt, Germany) at $37^{\circ} \mathrm{C}$ for 12 days; the medium refreshed every 3 days.

shRNA- and shNC-SW480 cells were transiently transfected with pReceiver-M02-E2F1 (pR-E2F1) or pReceiver-M02-control (pR-contol) (GeneCopoeia, Inc.) as aforementioned. In addition, CDCA3-SOE- and control-SOE-LoVo cells were transiently transfected with si-E2F1 or si-NC (GenePharma Co., Ltd, Shanghai, China) following the above process.

Colony formation assay. For colony formation assays, 500 SW480 cells transfected with siRNA1-CDCA3 or siNC, and CDCA3-OE-LoVo or cells with empty vectors (control-OE), were plated into 6 -well plates $48 \mathrm{~h}$ post-transfection. Following incubation at $37^{\circ} \mathrm{C}$ for 14 days, the clones were visible. Each well was washed with PBS three times, fixed with ethyl alcohol for $30 \mathrm{sec}$ and stained with $0.05 \%$ crystal violet for $20 \mathrm{~min}$ at room temperature. After washing, the colonies ( $\geq 50$ cells/colony) were counted using a Nikon TI-DH light microscope (Nikon Corporation, Tokyo, Japan) and images captured using a Canon DS126211 digital camera (Canon, Inc., Tokyo, Japan). In the later assays, shRNA- and shNC-SW480 cells transiently transfected with pReceiver-M02-E2F1 (pR-E2F1) or pReceiver-M02-control (pR-control) (GeneCopoeia, Inc.), as well as the CDCA3-SOE- and control-SOE-LoVo cells transiently transfected with si-E2F1 or si-NC (GenePharma Co., Ltd.), were plated into 6 -well plates $48 \mathrm{~h}$ following transfection and treated as aforementioned.
Cell proliferation assay. The Cell Counting Kit-8 (CCK-8; Dojindo Molecular Technologies, Inc., Kumamoto, Japan) assay was used to detect cell proliferation, according to the manufacturer's protocol. Cells $\left(2 \times 10^{3}\right.$ cells/well) were seeded in 96-well plates with $100 \mu \mathrm{l}$ complete culture medium. At 24, 48, 72 and $96 \mathrm{~h}$ incubation, $10 \mu \mathrm{l} \mathrm{CCK-8}$ was added to each well and the absorbance was measured $2 \mathrm{~h}$ later using a microplate reader at a test wavelength of $450 \mathrm{~nm}$ and a reference wavelength of $630 \mathrm{~nm}$. Experiments were performed in triplicate.

5-Ethynyl-2'-deoxyuridine (EdU) assay. The EdU assay kit (cat. no. C10310-3; Guangzhou RiboBio Co., Ltd., Guangzhou, China) was also used to measure cell proliferation. Briefly, cells were seeded $\left(2 \times 10^{4}\right.$ cells/well $)$ into 24 -well plates and cultured with DMEM for $24 \mathrm{~h}$. Subsequently, cells were incubated with EdU $(200 \mu \mathrm{l} ; 50 \mu \mathrm{M})$ for $2 \mathrm{~h}$ at $37^{\circ} \mathrm{C}$, fixed in $4 \%$ formaldehyde for $30 \mathrm{~min}$ and permeabilized at room temperature with $0.5 \%$ Triton $\mathrm{X}-100$ for $10 \mathrm{~min}$. A total of $400 \mu \mathrm{l} 1 \mathrm{X}$ ApolloR (every $400 \mu \mathrm{l}$ consists of $374.8 \mu \mathrm{l} \mathrm{H} \mathrm{H}_{2} \mathrm{O}$, $20 \mu \mathrm{l}$ reagent $\mathrm{B}, 4 \mu \mathrm{l}$ reagent $\mathrm{C}, 1.2 \mu \mathrm{l}$ reagent $\mathrm{D}$ and $4 \mathrm{mg}$ reagent $\mathrm{E})$ reaction cocktail was added and the cells were incubated for $30 \mathrm{~min}$; Hoechest $33342(400 \mu \mathrm{l})$ was added for $30 \mathrm{~min}$ to visualize the nuclei. A Nikon TI-DH light microscope (Nikon Corporation, Tokyo, Japan) was used to capture images of the cells. The mean number cells in three fields for each sample was calculated to assess cell proliferation.

Flow cytometric analysis of the cell cycle and apoptosis. Following $48 \mathrm{~h}$ transfection, cells were digested with trypsin and centrifuged at room temperature for $5 \mathrm{~min}$ at $300 \mathrm{x} \mathrm{g}$. Cells were washed carefully with PBS two times, fixed in $75 \%$ ethanol and stored at $-20^{\circ} \mathrm{C}$ overnight. Subsequently, the cells were washed twice with PBS and stained with propidium iodide (PI) staining solution $(500 \mu \mathrm{l})$ for $15 \mathrm{~min}$ at room temperature in the dark. Cell cycle analysis was performed using a fluorescence-activated cell sorting (FACS)Calibur flow cytometer with BD CellQuest software version 3.0 (BD Biosciences, Franklin Lakes, NJ, USA).

For apoptosis, cells were stained with PI $(10 \mu \mathrm{g} / \mathrm{ml}$; Sigma-Aldrich; Merck KGaA) and Annexin V-Fluorescein isothiocyanate $(50 \mu \mathrm{g} / \mathrm{ml}$; BD Biosciences) in the dark for $15 \mathrm{~min}$ at room temperature, according to the manufacturer's instructions. The data were acquired on a FACScan flow cytometer and analyzed using flow cytometry (both from BD Biosciences).

Western blotting. Protein lysates were prepared from the cells when they reached a density of $90 \%$ by using a Radioimmunoprecipitation assay kit (Beyotime Institute of Biotechnology, Shanghai, China), according to the manufacturer's protocols. The protein concentration was determined using the Bicinchoninic Acid Protein Assay kit (Beyotime Institute of Biotechnology). Proteins (40 $\mu \mathrm{g})$ of different molecular weights were separated on $10 \%$ SDS-PAGE and subsequently transferred to polyvinylidene difluoride membranes (EMD Millipore, Billerica, MA, USA). The membranes were blocked in 5\% non-fat milk at room temperature for $2-4 \mathrm{~h}$ and incubated at $4^{\circ} \mathrm{C}$ overnight with the primary antibodies. The membranes were subsequently incubated 
with anti-mouse or anti-rabbit immunoglobulin $\mathrm{G}$ at room temperature for $2 \mathrm{~h}$ and washed with TBS $+0.001 \%$ Tween-20 buffer three times. The protein bands were visualized using Enhanced Chemiluminescence Plus (EMD Millipore) with a Bio-Imaging System. The specific primary and secondary antibodies were as follows: polyclonal rabbit anti-CDCA3 (1:500; cat. no. ab167037); monoclonal rabbit anti-E2F1 (1:2,000; cat. no. ab179445); monoclonal rabbit anti-p21 (1:5,000; cat. no. ab109520); monoclonal rabbit anti-p27 KIP1 (1:5,000; cat. no. ab32034); monoclonal rabbit anti-cyclin-dependent kinase 2 (CDK2; 1:5,000; cat. no. ab32147) (all from Abcam); monoclonal rabbit anti-cyclin D1 (1:20,000; cat. no. ab134175); HRP-conjugated polyclonal anti-rabbit secondary antibody (1:5,000; cat. no. GAB007); and HRP-conjugated polyclonal anti-mouse secondary antibody (1:5,000; cat. no. GAM007) (both from Hangzhou MultiSciences (Lianke) Biotech Co., Ltd.). Monoclonal mouse anti- $\beta$-actin (1:5,000; cat. no. ab8226; Abcam) was used as an internal control.

Data of patients and samples from TCGA. RNA expression data (level 3) were downloaded from The Cancer Genome Atlas (TCGA; https://cancergenome.nih.gov) database, which provides normalized data by the RNASeq v2 system. The exclusion criteria were as follows: i) histological diagnosis revealed that the tissue was not $\mathrm{CRC}$; ii) patients suffered malignancies other than CRC; iii) samples without enough data for analysis; and iv) patients that have received preoperative radiotherapy and chemotherapy. Subsequently, a total of 337 tumor tissues were used in the study.

Functional enrichment analysis. Database for Annotation, Visualization and Integrated Discovery (DAVID) bioinformatics resources (https://david.ncifcrf.gov/) was used for the functional enrichment analysis, and the Gene Ontology (GO) biological processes and the Kyoto Encyclopedia of Genes and Genomes (KEGG) pathways. The criteria were set as $\mathrm{P}<0.05$ and an enrichment score $>1.5$.

In vivo tumor xenograft model. A total of $12 \mathrm{Balb} / \mathrm{c}$ nude male mice (age, 3-4 weeks; weight, 13-15 g) were purchased from the Animal Center of NJMU. The 12 mice were randomly divided into two groups ( $n=6$ per group) and were maintained at $20-26^{\circ} \mathrm{C}, 40-70 \%$ humidity, ammonia concentration $<14 \mathrm{mg} / \mathrm{m}^{3}$, with a $12-\mathrm{h}$ light/dark cycle and received $5 \mathrm{~g}$ food and $100 \mathrm{ml}$ water per $100 \mathrm{~g}$ body weight per day. A total of $2 \times 10^{6}$ stably transfected cells (shCDCA3 or shNC) were randomly and subcutaneously injected into each mouse in their right armpit. Bidimensional tumor measurements were taken with Vernier calipers every 4 days. All mice were sacrificed 4 weeks later and the tumors were surgically removed. Implanted tumor volume was calculated according to the following the formula: Volume $=\left(\right.$ width $^{2} \mathrm{x}$ length $) / 2$. Following sacrifice, tumor tissues were prepared for IHC as aforementioned and stained with rabbit monoclonal anti-Ki-67 (1:500; cat. no. ab92742; Abcam). The staining intensity was visually scored as follows (19): - (score 0$),+($ score 16), ++ (score 32) and +++ (score 50). The percentage scores were determined by half the percentage of Ki-67-positive cells, for example, $100 \% \mathrm{Ki}-67$-positive cells scored 50 . The final staining scores (a minimum value of 0 and a maximum of 100) were determined by the sum of the intensity and percentage scores. All animal experiments were approved and conducted according to the guidelines of The NJMU Institutional Animal Care and Use Committee.

Statistical analysis. Data are expressed as the mean \pm standard deviation. GraphPad Prism 5.0 software (GraphPad Software Inc., La Jolla, CA, USA) and the Statistical Program for Social Sciences 20.0 (IBM Corp., Armonk, NY, USA) were used to analyze the data. The clinical features were analyzed using $\chi^{2}$ test. The Wilcoxon rank-sum test was used to compare CDCA3 protein expression in CRC and adjacent normal tissue. Student's t-test was used to compare the treated and control groups. One-way analysis of variance and the least-significant difference post hoc test were used to compare data sets containing multiple groups. Pearson's correlation test was used to examine gene co-expressions; $r \geq 0.5$ was considered to indicate a relatively strong correlation. Cumulative survival analysis was assessed using the Kaplan-Meier method followed by log-rank test. $\mathrm{P}<0.05$ was considered to indicate a statistically significant difference.

\section{Results}

CDCA3 expression is increased in human CRC tissues and is associated with poor prognosis. To investigate the functional role of CDCA3 in CRC, the mRNA expression levels of CDCA3 were compared in 84 pairs of CRC and adjacent normal tissues using RT-qPCR, which indicated that CDCA3 expression was significantly higher in CRC tissues compared with adjacent normal tissue $(\mathrm{P}<0.001 ;$ Fig. 1A). The relationship between CDCA3 expression and clinicopathological features of patients with CRC was examined; the 84 CRC tissues were classified into two groups according to the median CDCA3 expression (10.15), high $(n=42)$ and low $(n=42)$ CDCA3 expression (Table I). Notably, high CDCA3 expression levels were significantly related with larger tumor size $(\mathrm{P}=0.001)$, TNM stage $(\mathrm{P}=0.049)$ and lymph node invasion $(\mathrm{P}=0.028)$. However, no significant differences were identified between CDCA3 expression and other features, such as age $(\mathrm{P}=0.243)$ and sex $(\mathrm{P}=0.507)$. Kaplan-Meier curve analysis indicated that the overall survival for patients with high CDCA3 expression was significantly shorter compared with patients with low CDCA 3 expression ( $\mathrm{P}=0.0048$; Fig. 1B). CDCA3 expression in $40 \mathrm{CRC}$ tissues and 40 adjacent normal specimens were detected by IHC. The results demonstrated that CDCA3 protein is mainly expressed in the cytoplasm and that CDCA3 protein was significantly overexpressed in cancerous tissues compared to adjacent normal tissues (Fig. 1C and Table II, respectively). These results indicated that the overexpression of CDCA3 may be related to poor prognosis of CRC.

Expression of CDCA3 is upregulated in CRC tissues and cell lines. To further investigate the functional role of CDCA3 in CRC cells, CDCA3 mRNA and protein expression levels were examined in six CRC cell lines using RT-qPCR and western blotting (Fig. 1D and E, respectively), which demonstrated that the expression of CDCA3 is upregulated in CRC cells. Subsequently, considering that SW480 cells presented high expression of CDCA3 and cultures 

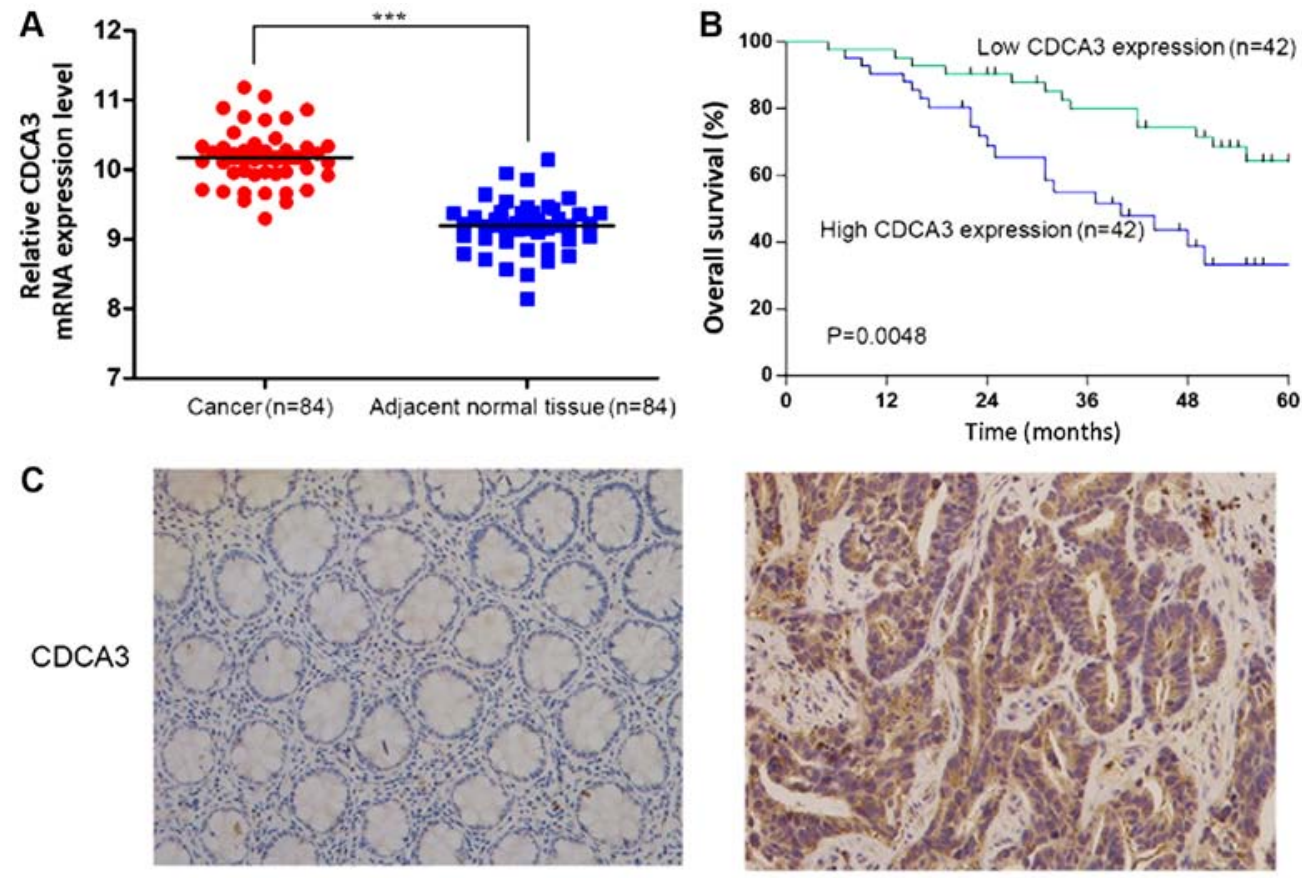

Adjacent normal tissue

CRC tissue

D

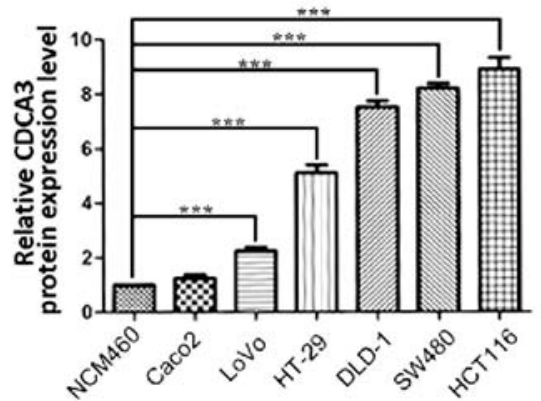

$\mathrm{E}$

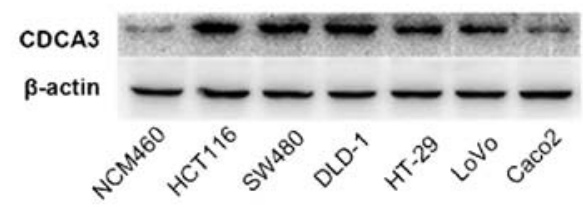

Figure 1. Expression of CDCA3 in CRC tissues and cell lines and Kaplan-Meier survival analysis. (A) Relative CDCA3 mRNA expression levels in 84 pairs of CRC tissues and adjacent normal tissues detected by RT-qPCR. (B) Kaplan-Meier survival analysis of 84 patients with CRC based on high or low CDCA3 expression levels. (C) CDCA3 protein expression was examined by immunohistochemistry in 40 CRC tissues and 21 adjacent normal specimens. (D and E) CDCA3 mRNA and protein expression levels were examined in six CRC cell lines using (D) RT-qPCR and (E) western blotting. Data are expressed as the mean \pm standard deviation; ${ }^{* * *} \mathrm{P}<0.001$. CDCA3, cell division cycle-associated protein 3; RT-qPCR, reverse transcription-quantitative polymerase chain reaction.

were easy to maintain, these cells were transiently transfected with siRNAs targeting CDCA3 (siRNA1-CDCA3, siRNA2-CDCA3 and siRNA3-CDCA3) or with siNC. RT-qPCR analysis was performed $48 \mathrm{~h}$ post-transfection and it was revealed that siRNA1-CDCA3 exhibited a higher efficiency of interference compared with siRNA2-CDCA3 and siRNA3-CDCA3 (Fig. 2A); siRNA1-CDCA3-transfected SW480 cells were selected for use in subsequent experiments and, for simplicity, will be referred to as siCDCA3. Considering that LoVo cells exhibited a relatively low level of CDCA3 expression of CDCA3, but still higher than NCM460 cells, LoVo cells were transiently transfected with either CDCA3 overexpression plasmids or with empty vector. The results of western blotting demonstrated that the expression level of CDCA3 was suppressed in siCDCA3-transfected SW480 cells and upregulated in CDCA3-OE-transfected LoVo cells (Fig. 2B).

Reduced CDCA3 expression inhibits cell growth in CRC cells. CDCA3 is a known 'trigger' of mitosis entry (7), it was hypothesized that CDCA3 may serve a role in CRC cell proliferation.
Results from CCK-8 assays indicated that siCDCA3-transfected CRC cells exhibited significantly decreased proliferation compared with cells transfected with siNC (Fig. 2C). EdU and Hoechst 33342 staining further confirmed that knockdown of CDCA3 expression significantly decreased the rate of proliferation (Fig. 2D). Similarly, colony-formation assay results demonstrated that CDCA3 knockdown significantly decreased clonogenic survival of SW480 cells (Fig. 2E). Conversely, CDCA3-OE-transfected LoVo cells exhibited significantly increased cell proliferation (Fig. 2C-E). Therefore, these results provided evidence that CDCA3 may promote proliferation in CRC cell lines.

CDCA3 influences the G1/S phase transition of the cell cycle by regulating p21 expression. To explore the possible roles of CDCA3 in influencing CRC cell proliferation, cell cycle distribution and apoptotic cell fraction were examined. To constitutively suppress or overexpress CDCA3, four stable cell lines were constructed: shCDCA3-SW480 and shNC-SW480, as well as CDCA3-SOE-LoVo and Control-SOE-LoVo. The efficiency of knockdown or overexpression was confirmed by 

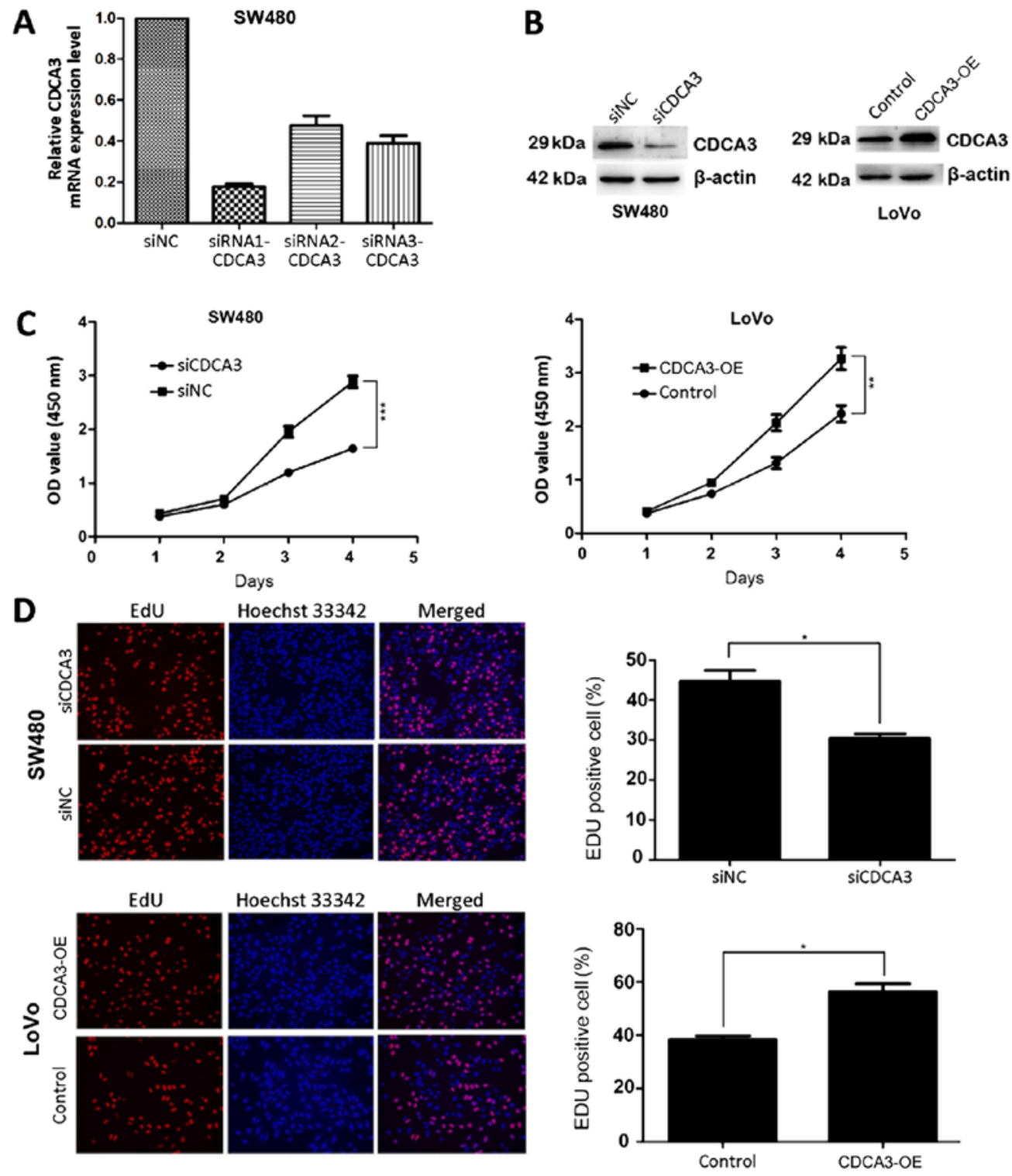

$\mathbf{E}$
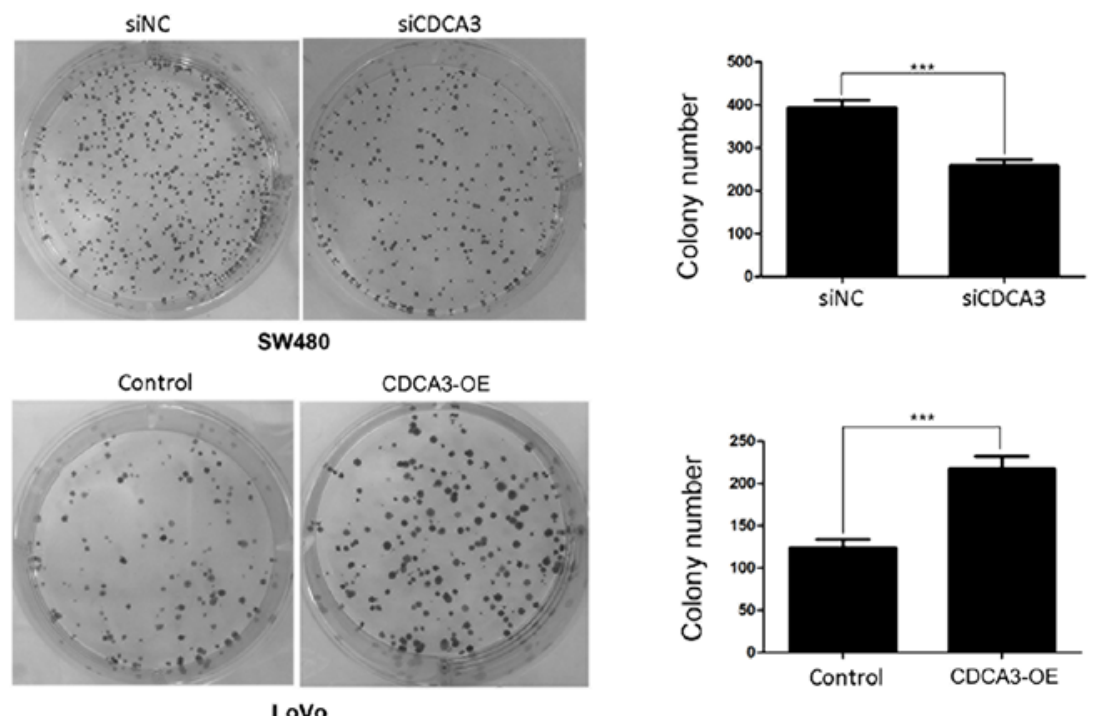

Figure 2. Expression of CDCA3 in CRC cells in loss or gain of function assays. (A) CDCA3 mRNA expression levels were examined by reverse transcriptionquantitative polymerase chain reaction in SW480 cells following transfection with different siRNAs against CDCA3 or siNC. (B-E) SW480 cells were transfected with siRNA1-CDCA3, and LoVo cells were transfected with CDCA3 overexpression vector and used to examine: (B) CDCA3 protein expression levels by western blotting; cell proliferation by (C) Cell counting kit-8 assays and (D) EdU staining assays; and (E) colony-formation ability. Representative images are presented in B, D and E. Data are presented as the mean \pm standard deviation from three independent experiments; ${ }^{*} \mathrm{P}<0.05,{ }^{* * *} \mathrm{P}<0.01$ and ${ }^{* * * *} \mathrm{P}<0.001$. CDCA3, cell division cycle-associated protein 3; CRC, colorectal cancer; EdU, 5-ethynyl-2'-deoxyuridine; NC, negative control; pR, pReceiver-M02; si, small interfering RNA. 
A
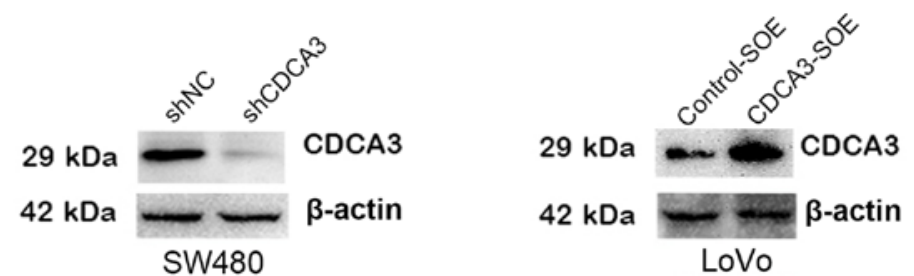

B
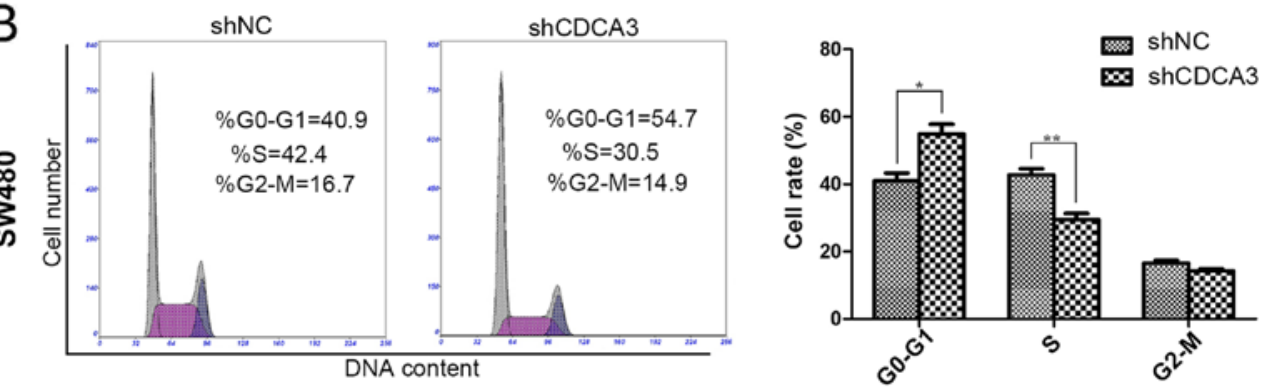

C
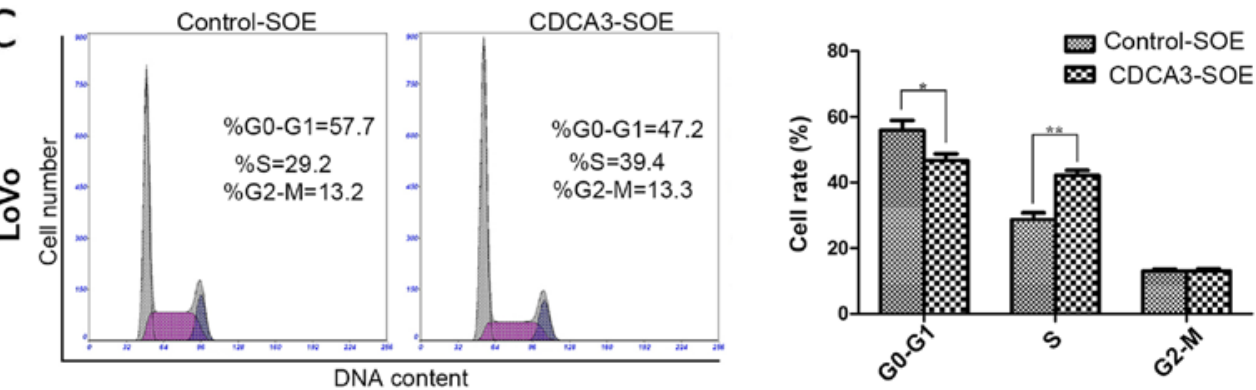

D
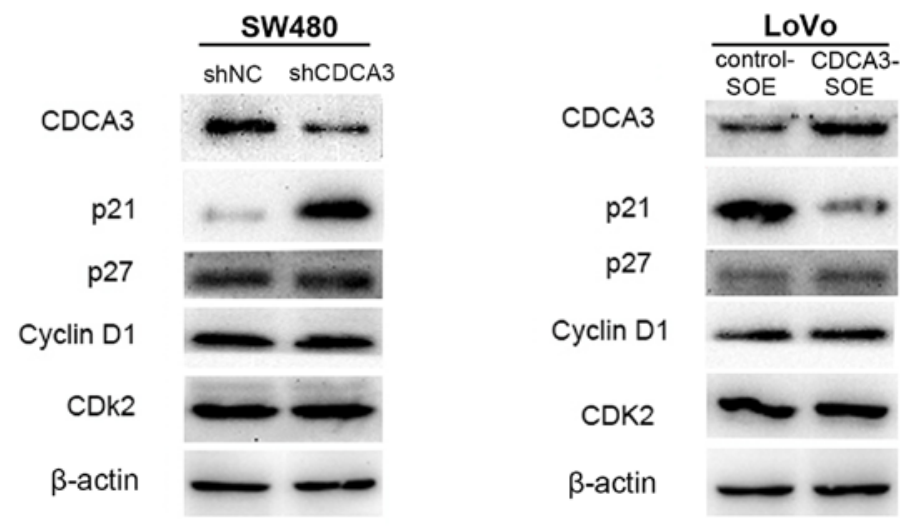

Figure 3. CDCA3 influences G1/S phase transition of the cell cycle by regulating p21 expression. (A) The efficiency of knockdown or overexpression was confirmed by western blotting detection of CDCA3 protein expression levels. (B) shCDCA3 notably increased the number of cells in G1 phase compared with the shNC control. (C) Overexpression of CDCA3 promoted the G1/S transition in LoVo cell lines. (D) Key regulators of the G1 phase were evaluated by western blotting. Data are presented as the mean \pm standard deviation; ${ }^{*} \mathrm{P}<0.05$ and ${ }^{* * *} \mathrm{P}<0.01$. CDCA3, cell division cycle-associated protein 3; CDK2, cyclin-dependent kinase 2; NC, negative control; sh, short hairpin RNA.

western blotting (Fig. 3A). shCDCA3 significantly increased the number of cells in G1 phase and decrease the number of cells in S phase compared with shNC (Fig. 3B). Conversely, CDCA3-SOE promoted the G1/S transition in LoVo cell lines (Fig. 3C). However, no significant difference was detected in the apoptotic cell fraction (data not shown). Expressions of key regulators of the G1 phase were evaluated by western blotting to clarify the role of CDCA3 in the G1/S phase transition. Knockdown of CDCA3 led to a notably increased expression of p21 in SW480 cells, whereas p21 expression was decreased in the CDCA3-overexpressing LoVo cells (Fig. 3D). No obvious differences were detected in the protein expression levels of p27, cyclin D1 or CDK2 proteins (Fig. 3D).
CDCA3 mediates p21-dependent proliferation by regulating E2F1 expression. To further explore the mechanism how CDCA3 mediates p21 expression, correlation analysis was performed using the R software (version 3.4.0) through analyzing the data obtained from TCGA. A total of 355 genes whose correlation coefficients were $\geq 0.5$ were selected. Subsequently, GO analysis and a KEGG pathway analysis were examined using DAVID to determine whether any GO terms or KEGG pathways were enriched. As observed from the gene enrichment of GO and KEGG analysis, the cell cycle is the largest group in both analyses (Fig. 4A and B, respectively). After selecting the intersection of the two groups, which contained 32 and 119 genes, respectively, 29 genes that may possibly 

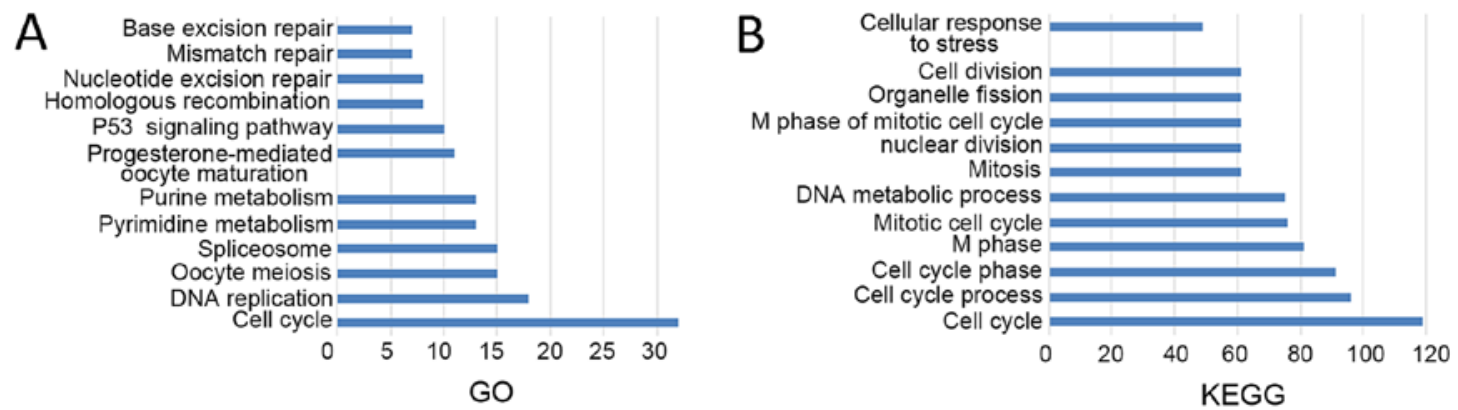

C

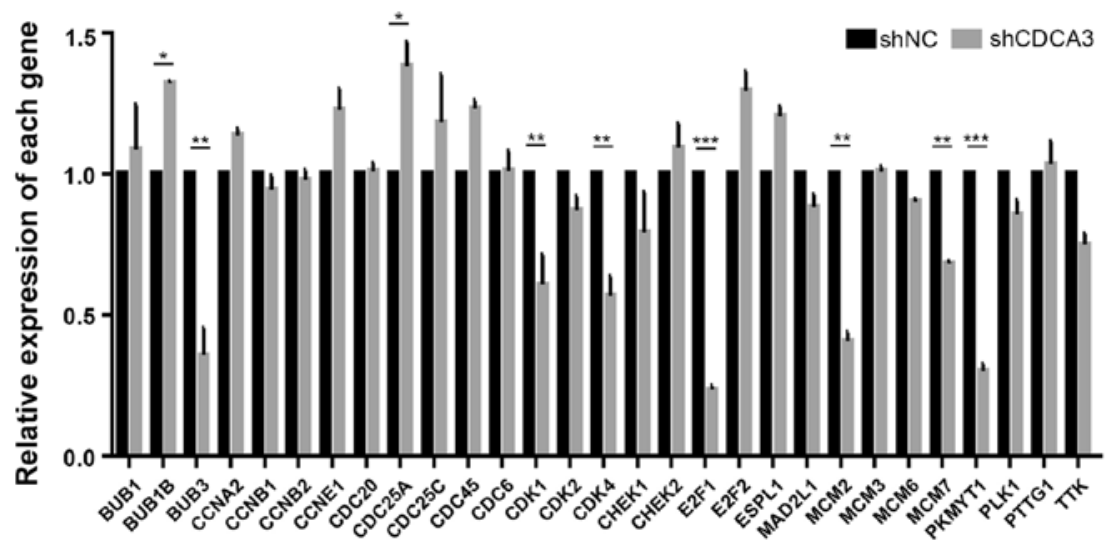

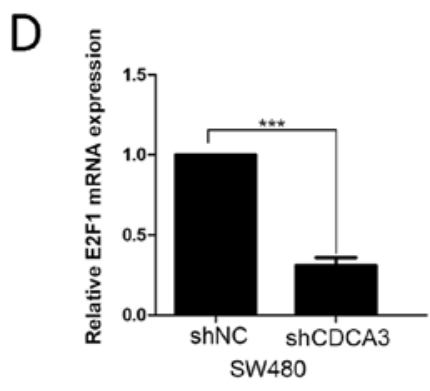

$\mathrm{E}$

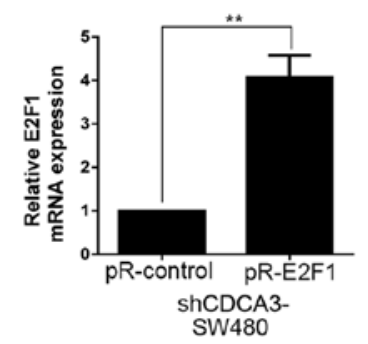

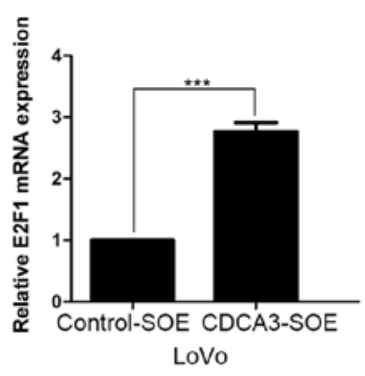

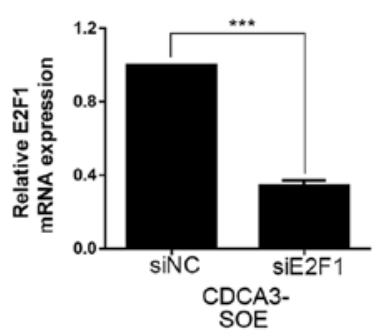

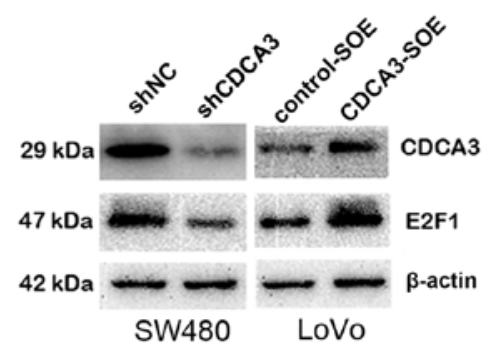

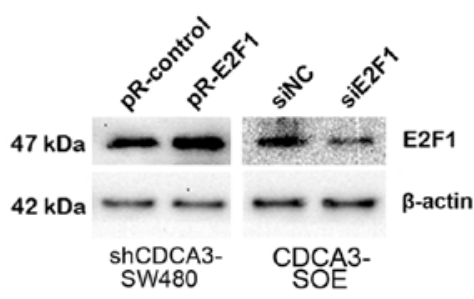

Figure 4. E2F1 may be a potential downstream target of CDCA3. (A) Gene ontology analysis of the selected 355 genes. (B) Kyoto Encyclopedia of Genes and Genomes pathway analysis of the selected 355 genes. (C) mRNA expression levels of 29 genes in shCDCA3-SW480 and shNC-SW480 cells. (D) E2F1 expression was detected by RT-qPCR and western blotting in SW480 and LoVo cells, respectively. (E) E2F1 expression levels were measured by RT-qPCR and western blotting following downregulation of CDCA3 in SW480 and upregulation of CDCA3 in LoVo cells. Results are presented as the mean \pm standard deviation; ${ }^{*} \mathrm{P}<0.05,{ }^{* *} \mathrm{P}<0.01$ and ${ }^{* * *} \mathrm{P}<0.001$. BUB1, BUB1 mitotic checkpoint serine/threonine kinase; BUB1B, BUB1 mitotic checkpoint serine/threonine kinase B; BUB3, BUB3 mitotic checkpoint protein; CCN, cyclin; CDC20, cell division cycle; CDCA3, cell division cycle-associated protein 3; CDK, cyclin-dependent kinase; CHEK, checkpoint kinase; ESPL1, extra spindle pole bodies-like 1, separase; MAD2L1, mitotic arrest deficient 2-like 1; MCM, minichromosome maintenance complex component; NC, negative control; PKMYT1, protein kinase, membrane-associated tyrosine/threonine 1; PLK1, polo-like kinase 1; PTTG1, pituitary tumor-transforming 1; RT-qPCR, reverse transcription-quantitative polymerase chain reaction; sh, short hairpin RNA; si, small interfering RNA; TTK, TTK protein kinase.

interact with CDCA3 were identified (Table IV). Subsequently, the mRNA expression levels of these 29 genes were determined in the shCDCA3-SW480 and shNC-SW480 cells. A significant difference in the expression levels of observed in two genes: E2F1 and protein kinase, membrane-associated tyrosine/threonine 1 (PKMYT1; Fig. 4C; $\mathrm{P}<0.001$ ). Following examination of previous literature, it was noted that $\mathrm{E} 2 \mathrm{~F} 1$ serves a crucial role in $\mathrm{CRC}$ and is an important molecular regulator upstream of p21 (20,21). Therefore, it was hypothesized that E2F1 may participate in the regulation of p21 expression by CDCA3.

To verify this hypothesis, E2F1 expression in shCDCA3SW480 and CDCA3-SOE-LoVo cells was examined using 
A
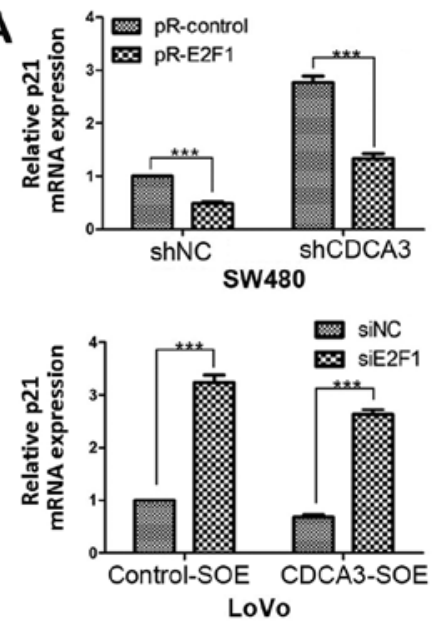

C

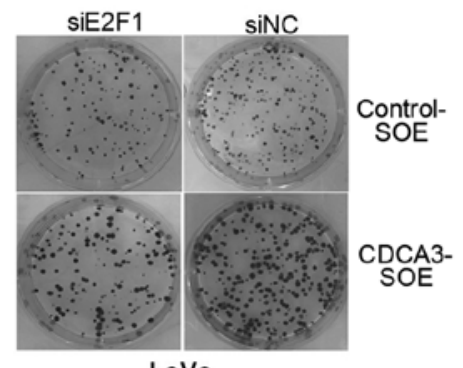

LoVo

D

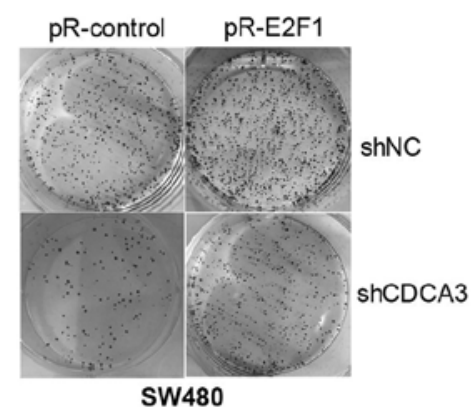

B
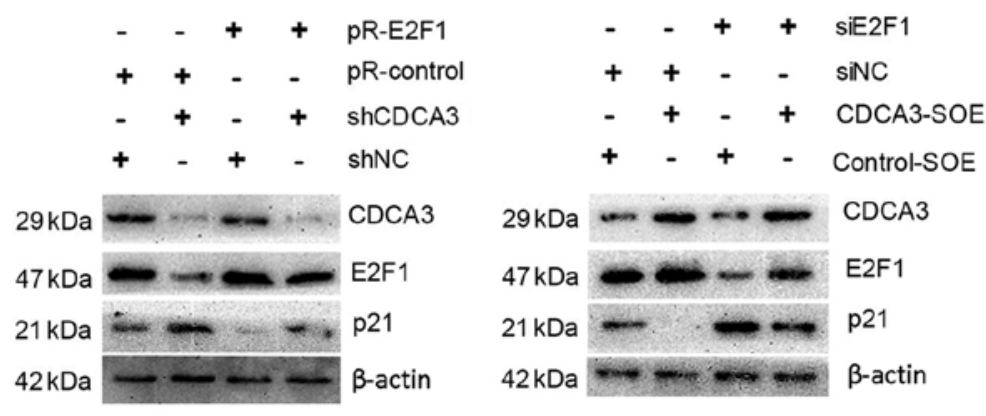
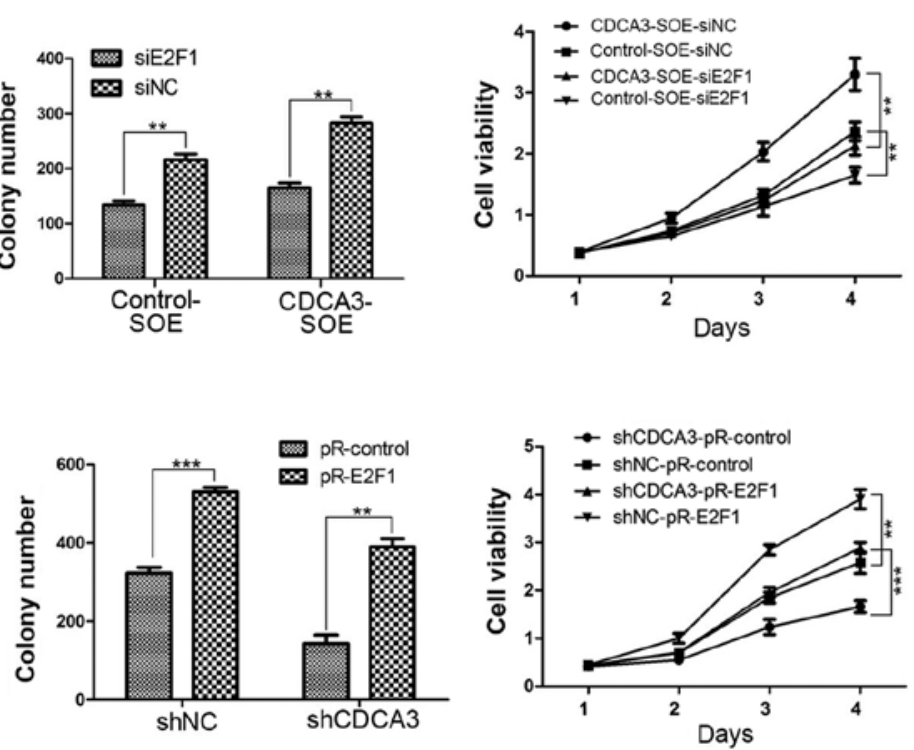

Figure 5. CDCA3 mediates p21-dependent proliferation by regulating E2F1 expression. (A) p21 mRNA expression was detected in the indicated stable cell lines transfected with pR-E2F1-overexpression or pR-Control vector. (B) Western blotting was used to detect the protein expression levels of CDCA3, E2F1 and p21 following the various treatments. (C and D) Representative images of colony formation and results from cell counting kit- 8 assays. Data are presented as the mean \pm standard deviation; ${ }^{* *} \mathrm{P}<0.01$ and ${ }^{* * *} \mathrm{P}<0.001$. CDCA3-SOE- and Control-SOE-LoVo cells represent the relatively stable overexpression of CDCA3 in LoVo cells. CDCA3, cell division cycle-associated protein 3; NC, negative control; pR, pReceiver-M02; sh, short hairpin RNA; si, small interfering RNA.

RT-qPCR and western blotting. The results demonstrated that E2F1 mRNA and protein expression levels were notably decreased shCDCA3-SW480 cells and increased in the CDCA3-SOE-LoVo cells (Fig. 4D). The efficiency of knockdown or overexpression of E2F1 by siE2F1 or pR-E2F1 transfection, respectively, was examined by RT-qPCR and western blotting (Fig.4E). The results demonstrated that expression of E2F1 was downregulated or upregulated by siE2F1 or pR-E2F1, respectively. Subsequently, E2F1-overexpression (pR-E2F1) or pR-Control vectors were transfected into the shCDCA3- or shNC-SW480 stable cell lines and siE2F1 or siNC were transfected into CDCA3-SOE- or control-SOELoVo stable cell lines. The results demonstrated that the p21 accumulation noted in shCDCA-SW480 cells was reduced when E2F1 was overexpressed compared with control cells, at both the mRNA and protein expression levels (Fig. 5A and B). Conversely, the reduced p21 expression observed in CDCA3SOE-LoVo cells was notably increased following transient transfection of siE2F1 in CDCA3-SOE cell lines compared with siNC-transfected cells (Fig. 5A and B).

Additional experiments were conducted to determine whether E2F1 was able to reverse the inhibition of proliferation induced by CDCA3 downregulation. The colony formation assay and CCK-8 assay indicated that overexpression of CDCA3 promoted cell proliferation in LoVo cells; however, this promotion of cell proliferation was inhibited by si-E2F1 (Fig. 5C). In addition, the results indicated that downregulation of CDCD3 suppressed cell proliferation in SW480 cells; however, the suppression of cell proliferation was reversed by overexpression of E2F1 (Fig. 5D). Taken together, these data suggested that CDCA 3 mediated p21 by regulating E2F1 expression.

Downregulation of CDCA3 inhibits CRC tumorigenesis in vivo. To further confirm the effects of CDCA3 in vivo, tumorigenesis assays were performed. shCDCA3-SW480 or 
Table IV. Correlation between the expression of CDCA3 and the other 29 genes.

\begin{tabular}{|c|c|c|c|c|c|}
\hline Gene symbol & P-value & R-value & Gene symbol & P-value & R-value \\
\hline BUB1 & $4.73 \mathrm{E}-32$ & 0.57 & CHEK1 & $1.23 \mathrm{E}-33$ & 0.59 \\
\hline BUB1B & $5.99 \mathrm{E}-30$ & 0.56 & CHEK2 & $1.67 \mathrm{E}-33$ & 0.58 \\
\hline BUB3 & $2.20 \mathrm{E}-26$ & 0.53 & $\mathrm{E} 2 \mathrm{~F} 1$ & $1.28 \mathrm{E}-40$ & 0.63 \\
\hline CCNA2 & $2.80 \mathrm{E}-51$ & 0.69 & E2F2 & $4.56 \mathrm{E}-33$ & 0.58 \\
\hline CCNB1 & $1.14 \mathrm{E}-55$ & 0.71 & ESPL1 & $4.82 \mathrm{E}-40$ & 0.63 \\
\hline $\mathrm{CCNB} 2$ & $1.13 \mathrm{E}-52$ & 0.70 & MAD2L1 & $5.38 \mathrm{E}-43$ & 0.65 \\
\hline CCNE1 & $5.87 \mathrm{E}-27$ & 0.53 & MCM2 & $1.73 \mathrm{E}-30$ & 0.56 \\
\hline CDC20 & $1.18 \mathrm{E}-56$ & 0.72 & MCM3 & $7.56 \mathrm{E}-26$ & 0.52 \\
\hline CDC25A & $7.50 \mathrm{E}-46$ & 0.66 & MCM6 & $8.27 \mathrm{E}-26$ & 0.52 \\
\hline CDC25C & $1.15 \mathrm{E}-52$ & 0.70 & MCM7 & $1.42 \mathrm{E}-33$ & 0.58 \\
\hline CDC45 & $1.13 \mathrm{E}-49$ & 0.68 & PKMYT1 & $3.15 \mathrm{E}-51$ & 0.69 \\
\hline CDC6 & $1.09 \mathrm{E}-32$ & 0.58 & PLK1 & $4.59 \mathrm{E}-56$ & 0.71 \\
\hline CDK1 & $2.73 \mathrm{E}-62$ & 0.74 & PTTG1 & $2.75 \mathrm{E}-60$ & 0.73 \\
\hline CDK2 & $1.26 \mathrm{E}-31$ & 0.57 & TTK & $1.58 \mathrm{E}-35$ & 0.60 \\
\hline CDK4 & $4.78 \mathrm{E}-33$ & 0.58 & & & \\
\hline
\end{tabular}

BUB1, BUB1 mitotic checkpoint serine/threonine kinase; BUB1B, BUB1 mitotic checkpoint serine/threonine kinase B; BUB3, BUB3 mitotic checkpoint protein; CCN, cyclin; CDC20, cell division cycle; CDK, cyclin-dependent kinase; CHEK, checkpoint kinase; ESPL1, extra spindle pole bodies-like 1, separase; MAD2L1, mitotic arrest deficient 2-like 1; MCM, minichromosome maintenance complex component; PKMYT1, protein kinase, membrane-associated tyrosine/threonine 1; PLK1, polo-like kinase 1; PTTG1, pituitary tumor-transforming 1; TTK, TTK protein kinase.

A

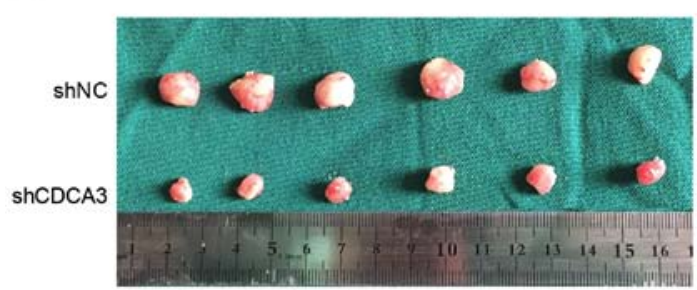

C

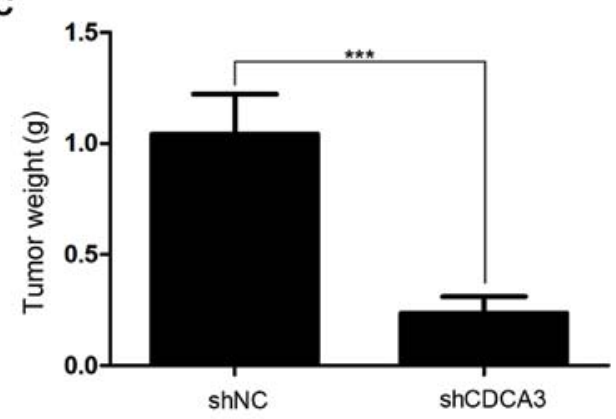

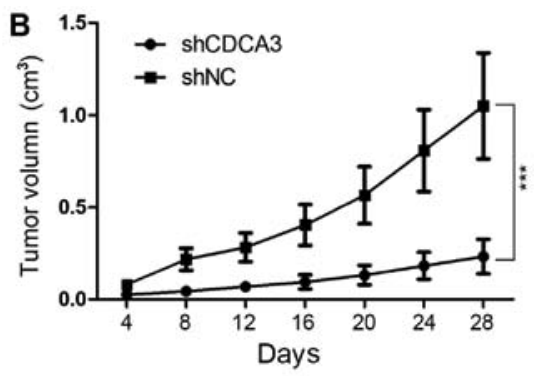

D

D $\quad$ ShNC
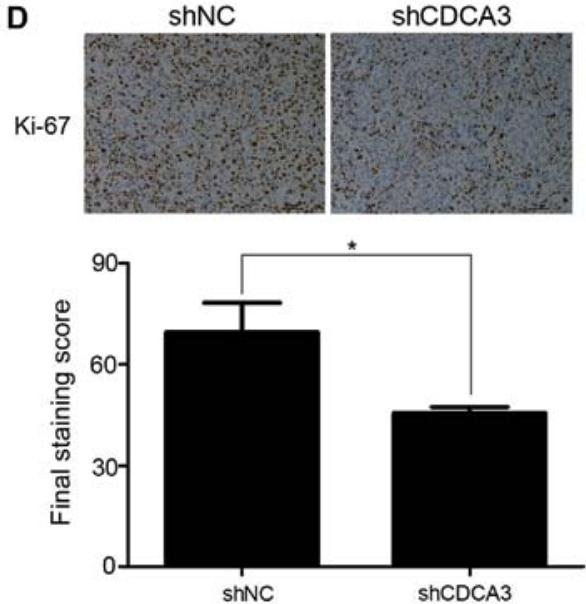

Figure 6. Downregulation of CDCA3 inhibits CRC tumorigenesis in vivo. (A-C) Tumor (A) size, (B) volume and (C) weight in the shCDCA3 group were significantly decreased compared with that in the shNC control group. (D) Tumors from the shCDCA3 group contain fewer Ki-67 positive cells compared with those from the shNC group. Data are presented as the mean \pm standard deviation; ${ }^{* * *} \mathrm{P}<0.001$. CDCA3, cell division cycle-associated protein 3 ; Ki- 67 , proliferation marker protein Ki-67; NC, negative control; sh, short hairpin RNA.

shNC-SW480 cells were injected subcutaneously into male nude Balb/c mice. Tumor size was measured every 4 days, and the tumor volume was calculated. All the mice had subcutaneous tumors at 4 weeks post-injection. Tumor size 
in the shCDCA3 group was notably smaller compared with the shNC group (Fig. 6A). In addition, tumor growth was slower (Fig. 6B) and the mean weight of shCDCA3 tumors was significantly lower in the shCDCA3 group compared with the shNC group (Fig. 6C). Results from the IHC assays indicated that tumors from the shCDCA3 group contain fewer $\mathrm{Ki}-67$ positive cells compared with those from the shNC group (Fig. 6D). These results further confirmed that CDCA3 may contribute to tumor proliferation in CRC.

\section{Discussion}

CDCA3 is part of the SCF E3 ligase complex that regulates mitotic entry (7). However, the molecular regulation of CDCA 3 and its functions may vary across malignancies of different origin. For example, in lung cancer, CDCA3 depletion was revealed to induce cell cycle arrest in the G2/M phase and apoptosis in non-small cell lung carcinoma cell lines (15). A previous bioinformatics study using a microarray data set of 163 tumor types reported a network of closely regulated genes that included CDCA3 with strong prognostic importance (22). The authors of that study verified the bioinformatics analysis results by RT-qPCR and demonstrated that CDCA3 transcripts were upregulated in breast, kidney, lung and ovarian cancers compared with expression levels in normal tissue. Results from the present study are consistent with previous studies, which reported that overexpression of CDCA3 in hepatoma cells promoted cell proliferation but did not affect apoptosis (22). Another previous study demonstrated that CDCA3 expression was increased in oral squamous cell carcinoma (14), and suppression of CDCA3 expression in oral cancer cells resulted in $\mathrm{G1} / \mathrm{S}$ phase cell cycle arrest and alterations in CDK or CDK inhibitor (CKI) expression. Consistently, the present study determined a defective cell cycle progression with an increased proportion of cells in the G1 phase following CDCA3 downregulation in CRC cell lines.

p21, one of the key regulators of cell cycle progression at the G1/S transition, serves a crucial role in tumorigenesis (23-25). p21 is widely accepted as a tumor suppressive protein and a negative regulator in the G1/S transition (26). A number of studies have reported that downregulation of p21 expression is involved in various human cancers and is correlated with cell growth $(27,28)$. p21 may acts independently as well as with other cell cycle regulators, such as CDK4/6 complex and p53 (29,30). The present study aimed to identify molecules that may be regulated by CDCA3 in the cell cycle, the expressions of several CDKs or CKI were detected by western blotting, and the results indicated that CDCA3 may upregulate p21 expression. Previous studies have demonstrated that E2F1 is an important mediator in modulating cell proliferation (21); E2F1 is an important molecular regulator upstream of p21 (31-33). In the present study, E2F1 exhibited a proliferation promoting effect, which was similar to previously published studies.

However, there are still many topics that remain to be explored. For example, the effects of CDCA3 on E2F1 and the mechanisms involved need further investigation. In addition, considering that CDCA3 expression is significantly associated with lymph node invasion in CRC, in vitro and in vivo experiments investigating the role of CDCA 3 in promoting metastasis and invasiveness are needed.
In conclusion, the results of the present study demonstrated that CDCA3 may target $\mathrm{p} 21$ to promote CRC cell proliferation and tumorigenesis, at least partially in an E2F1-mediated manner, and that CDCA3 may serve as a potential prognostic and therapeutic target of CRC.

\section{Acknowledgements}

The authors would like to thank the faculty and staff of the Department of General Surgery (First Affiliated Hospital of Nanjing Medical University, Jiangsu, China) for providing language and technology support.

\section{Funding}

The present study was funded by Jiangsu Key Medical DisciplineGeneral Surgery (grant no. ZDXKA2016005).

\section{Availability of data and materials}

The data sets used and/or analyzed during the current study are available from the corresponding author on reasonable request.

\section{Authors' contributions}

YS conceptualized and designed the research. WQ performed experiments, analyzed and interpreted the results, made figures and wrote the paper. ZZ, WP and JL performed experiments and analyzed data. JL provided patient tissues. QG, DJ, QW and YZ helped design the experimental studies and edited the manuscript. BJ, SW and DZ interpreted the results and wrote the manuscript. All authors have read and approved the manuscript.

\section{Ethics approval and consent to participate}

The present study was approved by the Research Ethics Committee of The First Affiliated Hospital of Nanjing Medical University and written informed consent was obtained from all patients prior to enrolment in the study.

\section{Patient consent for publication}

Not applicable.

\section{Competing interests}

The authors declare that they have no competing interests.

\section{References}

1. Siegel R, Desantis C and Jemal A: Colorectal cancer statistics, 2014. CA Cancer J Clin 64: 104-117, 2014.

2. Haggar FA and Boushey RP: Colorectal cancer epidemiology: Incidence, mortality, survival, and risk factors. Clin Colon Rectal Surg 22: 191-197, 2009.

3. Liu R, Huang S, Lei Y,Zhang T, Wang K, Liu B, Nice EC, Xiang R, Xie K, Li J, et al: FGF8 promotes colorectal cancer growth and metastasis by activating YAP1. Oncotarget 6: 935-952, 2015.

4. Chairatvit K and Ngamkitidechakul C: Control of cell proliferation via elevated NEDD8 conjugation in oral squamous cell carcinoma. Mol Cell Biochem 306: 163-169, 2007. 
5. Todd R, Hinds PW, Munger K, Rustgi AK, Opitz OG, Suliman Y and Wong DT: Cell cycle dysregulation in oral cancer. Crit Rev Oral Biol Med 13: 51-61, 2002.

6. Izzo JG, Papadimitrakopoulou VA, Li XQ, Ibarguen H, Lee JS, Ro JY, El-Naggar A, Hong WK and Hittelman WN: Dysregulated cyclin D1 expression early in head and neck tumorigenesis: In vivo evidence for an association with subsequent gene amplification Oncogene 17: 2313-2322, 1998.

7. Ayad NG, Rankin S, Murakami M, Jebanathirajah J, Gygi S and Kirschner MW: Tome-1, a trigger of mitotic entry, is degraded during G1 via the APC. Cell 113: 101-113, 2003.

8. Smith A, Simanski S, Fallahi M and Ayad NG: Redundant ubiquitin ligase activities regulate weel degradation and mitotic entry. Cell Cycle 6: 2795-2799, 2007.

9. Yoshida K: Cell-cycle-dependent regulation of the human and mouse Tome-1 promoters. FEBS Lett 579: 1488-1492, 2005.

10. Kraft C: Mitotic entry: Tipping the balance. Curr Biol 13 R445-R446, 2003.

11. Lim HH and Surana U: Tome-1, wee1, and the onset of mitosis: Coupled destruction for timely entry. Mol Cell 11: 845-846, 2003.

12. Jia L and Sun Y: RBX1/ROC1-SCF E3 ubiquitin ligase is required for mouse embryogenesis and cancer cell survival. Cell Div 4: 16, 2009.

13. Hu Q, Fu J, Luo B, Huang M, Guo W, Lin Y, Xie X and Xiao S OY-TES-1 may regulate the malignant behavior of liver cancer via NANOG, CD9, CCND2 and CDCA3: A bioinformatic analysis combine with RNAi and oligonucleotide microarray. Oncol Rep 33: 1965-1975, 2015.

14. Uchida F, Uzawa K, Kasamatsu A, Takatori H, Sakamoto Y, Ogawara K, Shiiba M, Tanzawa $\mathrm{H}$ and Bukawa H: Overexpression of cell cycle regulator CDCA3 promotes oral cancer progression by enhancing cell proliferation with prevention of G1 phase arrest. BMC Cancer 12: 321, 2012.

15. Adams MN, Burgess JT, He Y, Gately K, Snell C, Zhang SD Hooper JD, Richard DJ and O'Byrne KJ: Expression of CDCA3 is a prognostic biomarker and potential therapeutic target in non-small cell lung cancer. J Thorac Oncol 12: 1071-1084, 2017.

16. Chen J, Zhu S, Jiang N, Shang Z, Quan C and Niu Y: HoxB3 promotes prostate cancer cell progression by transactivating CDCA3. Cancer Lett 330: 217-224, 2013.

17. Benson AB III, Venook AP, Bekaii-Saab T, Chan E, Chen YJ, Cooper HS, Engstrom PF, Enzinger PC, Fenton MJ, Fuchs CS, et al; National Comprehensive Cancer Network: Colon cancer, version 3.2014. J Natl Compr Canc Netw 12: 1028-1059, 2014.

18. Livak KJ and Schmittgen TD: Analysis of relative gene expression data using real-time quantitative PCR and the 2(- $\Delta \Delta \mathrm{C}(\mathrm{T}))$ method. Methods 25: 402-408, 2001.

19. Sun J, Shi R, Zhao S, Li X, Lu S, Bu H, Ma X and Su C: E2F8, a direct target of miR-144, promotes papillary thyroid cancer progression via regulating cell cycle. J Exp Clin Cancer Res 36: 40, 2017.

20. Chen J, Gong C, Mao H, Li Z, Fang Z, Chen Q, Lin M, Jiang X, $\mathrm{Hu} \mathrm{Y}$, Wang W, et al: E2F1/SP3/STAT6 axis is required for IL-4-induced epithelial-mesenchymal transition of colorectal cancer cells. Int J Oncol 53: 567-578, 2018
21. Itzel T, Scholz P, Maass T, Krupp M, Marquardt JU, Strand S, Becker D, Staib F, Binder H, Roessler S, et al: Translating bioinformatics in oncology: Guilt-by-profiling analysis and identification of KIF18B and CDCA3 as novel driver genes in carcinogenesis. Bioinformatics 31: 216-224, 2015.

22. Egilmez R, Elagoz S and Kanik EA: Cdk1/P34Cdc2 and P21waf expression in colorectal adenomas and carcinomas. J Exp Clin Cancer Res 20: 549-552, 2001.

23. Pines J and Rieder CL: Re-staging mitosis: A contemporary view of mitotic progression. Nat Cell Biol 3: E3-E6, 2001

24. Calvisi DF, Donninger H, Vos MD, Birrer MJ, Gordon L, Leaner V and Clark GJ: NORE1A tumor suppressor candidate modulates p21CIP1 via p53. Cancer Res 69: 4629-4637, 2009.

25. Thaler S, Hähnel PS, Schad A, Dammann R and Schuler M: RASSF1A mediates p21Cip1/Waf1-dependent cell cycle arrest and senescence through modulation of the Raf-MEK-ERK pathway and inhibition of Akt. Cancer Res 69: 1748-1757, 2009.

26. Niculescu AB III, Chen X, Smeets M, Hengst L, Prives C and Reed SI: Effects of p21(Cip1/Waf1) at both the G1/S and the G2/M cell cycle transitions: $p R b$ is a critical determinant in blocking DNA replication and in preventing endoreduplication. Mol Cell Biol 18: 629-643, 1998.

27. Stein JP, Ginsberg DA, Grossfeld GD, Chatterjee SJ, Esrig D, Dickinson MG, Groshen S, Taylor CR, Jones PA, Skinner DG, et al: Effect of p21WAF1/CIP1 expression on tumor progression in bladder cancer. J Natl Cancer Inst 90: 1072-1079, 1998.

28. Cai K and Dynlacht BD: Activity and nature of p21(WAF1) complexes during the cell cycle. Proc Natl Acad Sci USA 95: 12254-12259, 1998.

29. Parker SB, Eichele G, Zhang P, Rawls A, Sands AT, Bradley A, Olson EN, Harper JW and Elledge SJ: p53-independent expression of p21Cip1 in muscle and other terminally differentiating cells. Science 267: 1024-1027, 1995.

30. Peng YP, Zhu Y, Yin LD, Zhang JJ, Wei JS, Liu X, Liu XC, Gao WT, Jiang KR and Miao Y: PEG10 overexpression induced by $\mathrm{E} 2 \mathrm{~F}-1$ promotes cell proliferation, migration, and invasion in pancreatic cancer. J Exp Clin Cancer Res 36: 30, 2017.

31. Teplyuk NM, Uhlmann EJ, Wong AH, Karmali P, Basu M, Gabriely G, Jain A, Wang Y, Chiocca EA, Stephens R, et al: MicroRNA-10b inhibition reduces E2F1-mediated transcription and miR-15/16 activity in glioblastoma. Oncotarget 6: 3770-3783, 2015.

32. Zhang E, Yin D, Han L, He X, Si X, Chen W, Xia R, Xu T, Gu D, De W, et al: E2F1-induced upregulation of long noncoding RNA LINC00668 predicts a poor prognosis of gastric cancer and promotes cell proliferation through epigenetically silencing of CKIs. Oncotarget 7: 23212-23226, 2016.

33. Feldstein O, Ben-Hamo R, Bashari D, Efroni S and Ginsberg D: RBM38 is a direct transcriptional target of E2F1 that limits E2F1-induced proliferation. Mol Cancer Res 10: 1169-1177, 2012.

This work is licensed under a Creative Commons Attribution-NonCommercial-NoDerivatives 4.0 International (CC BY-NC-ND 4.0) License. 